\title{
Flexible Manufacturing of Continuous Process Enterprises with Large Scale and Multiple Products*
}

\author{
Yigang Xu, Yifei Du, Yong Zeng, Shiming Li \\ School of Management and Economics, University of Electronic Science and Technology of China, Chengdu, China \\ Email: duyf@uestc.edu.cn
}

Received October 9, 2012; revised November 26, 2012; accepted December 3, 2012

\begin{abstract}
Compared with modularized enterprises, continuous Process (CP) enterprises exhibit differing characteristics in manufacturing flexibility. Relative to the vast literature on the flexibility of modularized enterprises, the manufacturing flexibility of CP enterprises has aroused little attention in current literature. In this paper, we develop a new theory to give a reasonable explanation for the flexible manufacturing problem of $\mathrm{CP}$ enterprises with multiple products. Based on the analysis of flexible manufacturing process of Jiahua enterprise, we find that CP enterprises can create product diversity through component flexibility, control flexibility and mixed flexibility. The discussion on the permutoid, arising from the product production transformation process of CP enterprises, further reveals the possibility of cost reduction in production transformation and thus efficiency enhancement of manufacturing flexibility. The cost-efficient flexibility of $\mathrm{CP}$ enterprises is realized by properly scheduling the production process, shortening the continuous transforming time of the permutoid and reverse development of the permutoid, with exploiting the characteristics of compatibility, continuity and reversibility of the permutoid. Finally, we conclude that the study on the manufacturing flexibility of CP enterprises will contribute to the flexible production transformation in the industries with CP.
\end{abstract}

Keywords: Continuous Process; Flexible Manufacturing; Permutoid; Case Study

\section{Introduction}

The keep-going high price motivates more consideration on energy-saving in the cement industry. Besides developing precalcining kiln technology, utilizing industrial waste heat and using frequency conversation technology largely, the production scale of a single cement production line has been expanded rapidly. In 2000, the average production capacity of a single production line of Chinese cement industry was 85200 tons clinker per year, the average coal consumption of one ton clinker was $156.35 \mathrm{~kg}$ standard coal, there were only 11 precalcining kiln production lines whose daily production capacity were above 4000 tons and there was not a single production line with 10,000 tons daily production capacity. Whereas in 2010 the average production capacity of a single production line reached 1 million tons clinker per year, the average coal consumption of one ton clinker was $115 \mathrm{~kg}$ standard coal, there were 860 precalcining kiln production lines whose daily production capacity were above 4000 tons and there were 7 precalcining kiln production lines with 10,000 tons daily production ca-

*This project is supported by the National Natural Science Fund of China (Project No. 71272131). pacity $^{1}$. This development phenomenon can also be observed from the industries such as glass industry, metallurgy industry, chemical industry, oil refining industry and so on.

The rapid expansion of the production scale created chances for cement enterprises to reduce energy consumption and made large production lines win cost advantage over small ones. Under the condition of serious overcapacity, the continuous low cement price forced many small common cement enterprises to close their small cement kilns.

It's obvious that the small cement clinker production line is getting more and more uncompetitive on cost. For the special cement production enterprises, they are facing a new challenge, which is how to revolute under the condition of cost pressure and how to keep the former production mode of multiple small production lines with single product in a single production line in such difficult situation. Under the condition of limited order for a single product, expanding the production scale of a single production line means the needs to change the production mode, that is to say the cement enterprise will certainly produce multiple cement clinker products in a single

\footnotetext{
${ }^{1}$ Source: “Digital Cement Net” of China Cement Association.
} 
large production line, which is the focus issue of our research.

The production process of cement clinker is a continuous manufacturing process, which is apparently different from the modular production we normally understand. In a continuous production industry, what push flexible manufacturing of multiple products and whether there exist other flexible strategies which differ from the modular production. As the current theoretical models pay less attention to CP enterprise, we discuss and analyze the case of flexible manufacturing of Jiahua enterprise which is the largest special cement production enterprise of China and try to develop a new theoretical model which can describe and explain the multiple products flexible manufacturing of CP enterprise.

The paper contains four parts. The first part is introduction. The second part review related theoretical research, such as mass customization, flexible manufacturing and modularity theory. The third part is specific case analysis and discovery. And the forth part establishes conceptual frameworks for the multiple products flexible manufacturing of CP enterprise based on the case study. Finally, the fifth party is the discussion and conclusion of the paper, which points out the meaning of the research and scope of application, illustrates the further research directions.

\section{Related Research}

\subsection{Mass Customization, Flexible Manufacturing and Modularity}

Mass customization (MC) is a production method coming from the diversity of customer demand and development of information technology in 1990s. Joseph Pine systematically studied MC earlier, who thought that the core of MC is the diversity of product types and sharp increase of customization requirements without increasing cost, and the scope is the large scale production of personalized customization products and services and the largest advantage is providing strategic advantage and economic values (Pine, 1992) [1]. Actually MC provides two new insights for us. One is the ability to provide every customization product on the position of customers at the time, place and in a mode customers anticipate. The other one is producing multiple products rapidly with the cost of large scale production through flexible organization, equipments and processes on the position of enterprise (Hart, 1995) [2].

The multiple and customized product put forward higher requirements for the product producing ability of the enterprise. The traditional rigid production line is specially designed for a single product, which can't satisfy the manufacturing requirement of multiplication and customization. MC requires enterprise to have flexible product producing ability. It mainly constructs and promotes the flexible product producing ability of the enterprise through flexible manufacturing system (FMS), effective integration of networked manufacture and flexible management of the enterprise (Dai \& Guo, 2006) [3]. The functions of FMS are mainly embodied on the two aspects: one is from the flexibility in the product manufacturing process, the other is the flexibility that influences and determines the production (Sethi \& Sethi, 1990) [4].

The promotion of the enterprise's flexible manufacturing level should be realized by low cost, which is the key for the enterprise to run in MC mode. The best way to realize MC is to establish a modularity component which can configure multiple products and services with the lowest cost and highest individuation level (Pine, 1992).

Masahi ko Aoki (2003) [5] promotes the definition of the module based on studying the definitions of many modules, who thought that the module is a semi-selfdiscipline subsystem that can consist of systematic and specific independent function. The modules interconnect by certain rules through standard surface structure and other functional semi-self-discipline subsystems to construct a more complicated system or process. The modules should have the following characteristics: 1) independence: that means the module can be designed individually, innovated freely and the design concept will not be influenced by other subsystems; 2) relation: that means all modules follow common design rules which should have stable external interfaces and the modules with the same external interface can be interchanged; 3) structural function: that means the modules can not exist and work alone, they need to connect with each other to establish a more complicated system.

Modularity production has apparent function on reducing cost (Gu \& Qi, 2001) [6] because modularity design is to produce large quantity products by composing limited universal modules and standard modules, whereas universal modules and standard modules can realize the production in large scale and low cost (Zhang, 2010) [7]. Therefore, the production problem of customized products is transformed or partly transformed into the mass production problem, which helps enterprise to produce the product of any quantity for a single customer or small scale and multiple products market with the cost and speed of large scale production (Anderson \& Pine, 1997) [8].

Similarly, the flexibility of the enterprise represents the adaptability for the enterprise to the external changes, and the strategy established on the modularity basis is the best way to deal with changes (Baldwin \& Clark, 1997) [9]. Baldwin and Clark (2000) [10] furthermore studied the ways to create diversified products by modularity design. They promoted that six simple instruction char- 
acteristics which are splitting, substituting, augmenting, excluding, inverting and porting can realize the diversity of product design.

\subsection{Continuous Process}

Continuous Process (CP) is a process that the raw materials are put into a station and run through the assembly line in a certain order until the finished products are produced in the end. The technology process of CP is sequent and the physical structure of the product of CP is inseparable. The production process is put in use in some industries, such as metal-refractory industry, papermaking industry and chemical industry all belong to CP (Wang, 2011) [11].

Under the condition of a certain technology process control, as the process of CP from input of the material and output of the product is continual, which involves many kinds of transforming process such as separation, decomposition, recombination and composition of material, the mode of $\mathrm{CP}$ is a non-modularity production mode.

It can be concluded following discrepancy between CP and modularity process. First, in CP the production line for the material's input and output is a complete system, the termination of any link in the production chain will block the system and influence the quality and quantity of the output product, whereas the production line system of modularity process is separable and combined. Second, the materials of CP will experience a serious of process of separation, decomposition or combination under the control of a certain technology process, which is difficult to be separated to independent subsystems, whereas modular enterprises actually combine each independent module to form a more complicated system in a certain structural way. Third, in CP, the production transformation of multiple products in a single production line is arranged in time order and can't be parallel to the modular enterprises to implement the production.

As the current theoretical models mainly study the MC and flexible manufacturing problem based on modularity process enterprises, which is difficult to explain and illustrate some key strategies of flexible manufacturing of the production enterprise. In this essay we try to develop a new theoretical model to explain the multiple products flexible manufacturing of CP enterprise, which is different from that of modularity process enterprises.

\section{An Investigation on the Flexible Manufacturing with Multiple Products}

\subsection{Settings}

Jiahua enterprise is one of the largest special cement enterprises of China at present and one of the fastestgrowing special cement enterprises in recent years. At present Jiahua enterprise owns five factories (See Table 1) which are separately located in Leshan City, Emeishan City, Pengzhou City, Mianning County of Liangshan City and Pingshan County of Shijiazhuang City. As the differences of product types and factory locations and each factory has its independent customer group, except the factory in Mianning County of Liangshan State has two 2500T/D precalcining kiln production lines, other

Table 1. The distribution chart of sub-factories of Jiahua enterprise.

\begin{tabular}{|c|c|c|c|c|}
\hline Name of factory & Scale of production line & Location & Production type & Note \\
\hline $\begin{array}{l}\text { Leshan Jiahua Cement } \\
\text { Factory }\end{array}$ & $\begin{array}{l}\text { One } 1800 \mathrm{~T} / \mathrm{D} \\
\text { precalcining kiln } \\
\text { production line }\end{array}$ & $\begin{array}{l}\text { Jianong Town, } \\
\text { Shawan District, } \\
\text { Leshan City, Sichuan } \\
\text { Province }\end{array}$ & $\begin{array}{l}\text { All kinds of hydraulic engineering } \\
\text { and oil well cement and related } \\
\text { customer-specific products of the } \\
\text { above cement system }\end{array}$ & \\
\hline $\begin{array}{l}\text { Emeishan Qianghua } \\
\text { Special Cement } \\
\text { Company of Limited } \\
\text { Liability }\end{array}$ & $\begin{array}{l}\text { One } 500 \mathrm{~T} / \mathrm{D} \\
\text { precalcining kiln } \\
\text { production line }\end{array}$ & $\begin{array}{l}\text { Longchi Town, } \\
\text { Emeishan City, } \\
\text { Sichuan Province }\end{array}$ & $\begin{array}{l}\text { All kinds of decoration and thermo } \\
\text { technical cement and related } \\
\text { customer-specific products of the } \\
\text { above cement system }\end{array}$ & \\
\hline $\begin{array}{l}\text { Chengdu Jiahua Special } \\
\text { Engineering Material } \\
\text { Company of Limited } \\
\text { Liability }\end{array}$ & $\begin{array}{l}\text { One } 1200 \mathrm{~T} / \mathrm{D} \\
\text { precalcining kiln } \\
\text { production line }\end{array}$ & $\begin{array}{l}\text { Xiaoyudong Town, } \\
\text { Pengzhou, Chengdu } \\
\text { City, Sichuan } \\
\text { Province }\end{array}$ & $\begin{array}{l}\text { All kinds of oil well and road } \\
\text { cement and related } \\
\text { customer-specific products of the } \\
\text { above cement system }\end{array}$ & \\
\hline $\begin{array}{l}\text { Sichuan Jiahua Jinping } \\
\text { Special Cement } \\
\text { Company of Limited } \\
\text { Liability }\end{array}$ & $\begin{array}{l}\text { Two } 2500 \mathrm{~T} / \mathrm{D} \\
\text { precalcining kiln } \\
\text { production lines }\end{array}$ & $\begin{array}{l}\text { Lugu Town, } \\
\text { Mianning County of } \\
\text { Liangshan State, } \\
\text { Sichuan Province }\end{array}$ & $\begin{array}{l}\text { All kinds of hydraulic engineering } \\
\text { and road cement and related } \\
\text { customer-specific products of the } \\
\text { above cement system }\end{array}$ & $\begin{array}{l}\text { The second production line } \\
\text { was started production in } \\
\text { April } 2012 \text { and is now in the } \\
\text { process of debug and pilot } \\
\text { run }\end{array}$ \\
\hline $\begin{array}{l}\text { Shijiazhuang Jiahua } \\
\text { Special Engineering } \\
\text { Material Company of } \\
\text { Limited Liability }\end{array}$ & $\begin{array}{l}\text { One } 1000 \mathrm{~T} / \mathrm{D} \\
\text { precalcining kiln } \\
\text { production line }\end{array}$ & $\begin{array}{l}\text { Pingshan Town, } \\
\text { Pingshan County, } \\
\text { Shijiazhuang City, } \\
\text { Hebei Province }\end{array}$ & $\begin{array}{l}\text { All kinds of oil well cement and } \\
\text { related customer-specific products } \\
\text { of the above cement system }\end{array}$ & \\
\hline
\end{tabular}

Source: Inside information of Jiahua enterprise. 
factories only have one production line and each production line should produce multiple products according to the personalized requirement of customer. And the actual situation is the second production line of the factory in Mianning County of Liangshan State is now in the process of debug and pilot run, so the factory is actually mainly running in single production line.

The production process of cement clinker mainly depends on industrial long kiln and calciner. The characteristic of CP from the raw material input and the cement clinker output is typical. Generally speaking, the common cement enterprises only produce standard common Portland cement clinker, so there is not the problem of multiple products production in a single production line during the calcining process. However, special cement enterprises are exceptions as the production line should satisfy the requirement of flexible manufacturing for different kinds of clinker of different kinds of special cement in a single production line. Therefore, it can be observed the flexible manufacturing process and characteristic of CP enterprise from Jiahua enterprise.

The early special cement businesses of Jiahua enterprise mainly focused on the production of oil well cement. As the scale of the production line was small and the main production line was a 50,000 tons/year vertical cylinder preheater kiln, the factory usually produced in the way of single product in a single production line. In 2000 the cost of coal only counted to $17 \%$ of the cement clinker cost, while the price of coal had been grown higher and higher after 2003 and in 2006 the cost of coal counted to $40 \%$ of the cement clinker cost. As the energy consumption of small vertical cylinder preheater was too much and competitiveness pressure, in April 2008 Jiahua enterprise changed the vertical cylinder preheater kiln of Emeishan Qianghua Special Cement Company of Limited Liability to be new dry process precalcining kiln, of which the production capacity was 200,000 tons cement clinker per year. It was the first precalcining kiln production line of the enterprise.

Except improving the production capacity, the development of hydraulic engineering market of Jiahua enterprise promoted the requirement of producing multiple products in the same production line of Emeishan Qianghua Company. At the same time, Jiahua enterprise got the order of the special cement for dam impervious wall from China Guodian Dadu River Hydropower Development Co., Ltd. Pubugou Hydropower Station and moderate heat Portland cement from Sinohydro Corporation Shawan Hydropower Station. Plus the original class G oil well cement, Emeishan Qianghua Company tried to produce three kinds of products in the same production line and made preliminary success.

In May 2009, a new 2000T/D (600,000 tons clinker per year) new dry process precalcining kiln production line in Shawan District established by Jiahua enterprise was put into production. In July 2009, Jiahua enterprise acquired Jinping Special Cement Company in Mianning County Liangshan State which had a 2500T/D (775,000 tons clinker per year) new dry process precalcining kiln production line at that time and the second 2500T/D new dry process precalcining kiln production line was completed in 2012. After that, Jiahua enterprise owned two factories in Pengzhou City, Sichuan Province and Pingshan County, Shijiazhuang City, Hebei Province by technology reformation and acquisition. At the same time, the enterprise phased out all small cement kiln production lines and replaced with precalcining kiln production line so that the scale of production line of Jiahua enterprise improved to a new level.

In recent years the enterprise's business has been extended to the areas such as decoration, nuclear engineering, marine engineering and transportation from oil well industry and hydraulic engineering industry. In December 2009, the general manager of the enterprise clearly pointed out in the annual work report that Jiahua enterprise would be positioned on "the manufacturer of cement-based functional material and supplier of application solutions". In order to adapt to the enterprise's development strategy, the enterprise is also trying to construct a kind of large scale flexible manufacturing mode which can rapidly respond to customer's requirement in manufacturing process.

As a strategic consideration, the enterprise must push flexible manufacturing mode to the systematic production mode. From that time all five factories of the enterprise began to carry out manufacturing flexibility production.

\subsection{CP in the Special Cement Production}

All special cement production lines of Jiahua enterprise use new dry process precalcining process. Usually the special cement is produced by grinding special cement clinker and each kind of special cement has unique corresponding relationship with its clinker. For the convenience of study, the essay only takes the production process of clinker as the process of CP to discuss the case.

The production process of special cement mainly includes all the CP from prepare raw meal burden to calcine at high temperature in kiln until the clinker output, such as preheating, decomposion, calcine, cooling and output process, all of which are integrated controlled by central control system. The burden of raw meal is mainly carried out according to the difference of the product type of special cement. If the product belongs to Portland series, the raw meals are mainly limestone and all kinds of siliceous material, ferruginous material or aluminous calibration material. If the product doesn't belong to Portland series, it needs to add other materials such as 
sulfide, phosphide or fluoride into limestone and bauxite to form the cement minerals such as aluminates, sulpho-aluminates, phosapholuminates or fluoroaluminates. The control methods of technology process mainly includes the control of preheater, calciner, kiln system (the head, middle part and end of the kiln), the temperature of cooling machine; the air volume, air speed and pressure of the pipes connecting equipment system; the rotary speed and flow rate and speed of the material of rotary kiln system; the place, pressure and coal's flow speed of kiln head; the appearance of the flame in kiln head and so on.

Take the production process of Portland series special cement clinker for example, after the raw meal goes into the kiln, firstly the preheater will heat the raw meal by the waste heat of the waste gas exhausted from rotary kiln and calciner to preheat the raw meal and decompose a part of carbonates; secondly the calciner will decompose the preheated material rapidly at suspended status or fluidized status to make the decomposition rate of raw meal above $90 \%$; thirdly the rotary kiln will calcine the pre-decomposed material to make carbonates decompose more quickly and perform a series of solid status reactions to form the minerals such as $\mathrm{C}_{2} \mathrm{~S}, \mathrm{C}_{3} \mathrm{~A}$ and $\mathrm{C}_{4} \mathrm{AF}$ in cement clinker. With the temperature of the material increases to approach $1300^{\circ} \mathrm{C}$, the minerals such as $\mathrm{C}_{2} \mathrm{~S}$, $\mathrm{C}_{3} \mathrm{~A}$ and $\mathrm{C}_{4} \mathrm{AF}$ will become liquid status. At this time $\mathrm{C}_{2} \mathrm{~S}$ dissolved in the liquid status will react with $\mathrm{CaO}$ to form a large number of $\mathrm{C}_{3} \mathrm{~S}$. After the clinker is sintered, the cooler of cement clinker will cool the high temperature from rotary kiln and then transform to the clinker storehouse It can be seen from the above technical process (Figure 1) that the production of special cement clinker is finished in the precalcining system. The precalcining kiln is a continuous production system composed by preheater, calciner, and rotary kiln and cooler, which is a closed system. The raw meal experiences a uniform motion process inside the kiln system from being input to output of the kiln, during which time the material experiences a series of physical and chemical reactions inside the system by the large number of energy changes between materials and finally form clinker product.

Central control room is a product by combining calcining technology and computer integration technology, which is established on the basis of the information change between kiln system and outside operators. Usually a complete clinker production line will have 3000 5000 data collection points, which will be reflected on the computer screen in central control room after been integrated and analyzed and according to the analysis result of the data the operators in central control room can prejudge the running status of the kiln system and instruct adjusting the method and parameters of process technology control so as to control the system.

\subsection{Adjustment on Components of Raw Material and Control Methods}

The manufacturing flexibility of multiple special cement products of Jiahua enterprise is realized by adjusting components of raw material and changing the control methods of clinker calcinations process. Table 2 listed the components of raw material and the finished clinker of six different kinds of special cement products. The variability of components lead to the variety of products.

Table 3 shows the adjustment of parameter of technology process control promotes the product variety under the condition without changing raw material consituents.

Table 4 listed the method and parameter of process technology control of six kinds of special cement products. The changes of method and parameter of process technology control lead to the variety of products.

\subsection{Flexible Production Exploration}

\subsubsection{Development of Product Sequencing Technology}

In the practices of product conversions, the technicians of Jiahua enterprise found that the conversions between some kinds of products would be very smooth, while some other kinds of products would be very difficult,

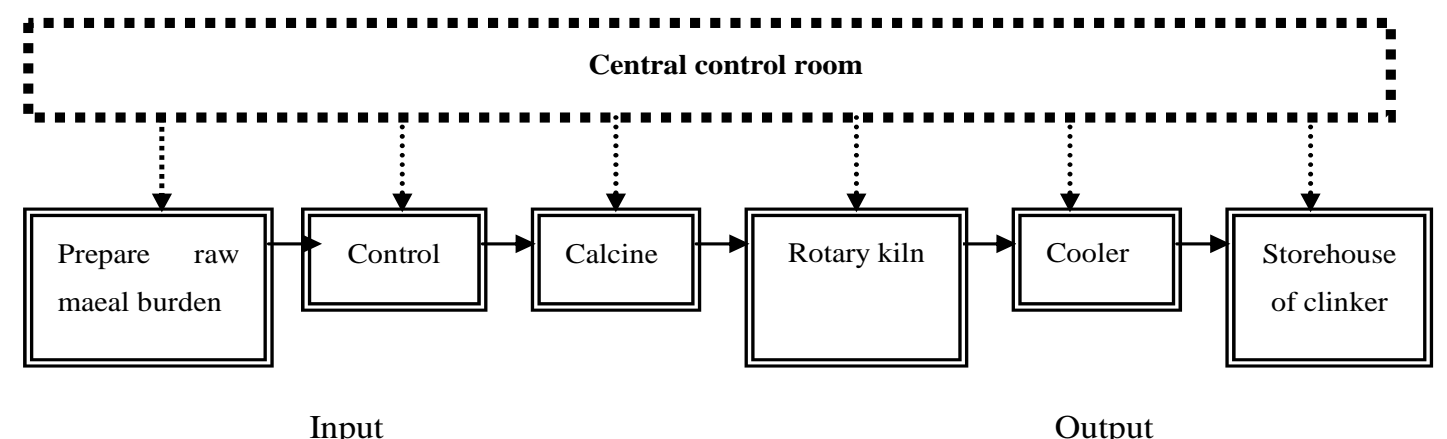

Figure 1. The technology process of special cement clinker production. 
Table 2. The components of a part of special cement products of Jiahua enterprise.

\begin{tabular}{|c|c|c|c|c|c|c|c|c|c|c|c|c|c|c|c|}
\hline \multirow{2}{*}{ 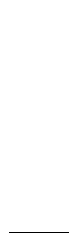 } & \multirow{2}{*}{ Product } & \multicolumn{6}{|c|}{ Raw meal } & \multirow{2}{*}{\multicolumn{2}{|c|}{ Product }} & \multicolumn{6}{|c|}{ Clinker } \\
\hline & & 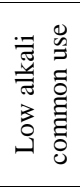 & $\begin{array}{l}\overline{\overline{0}} \\
3 \\
\overline{0} \\
0 \\
0 \\
0 \\
0 \\
0\end{array}$ & 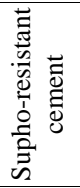 & 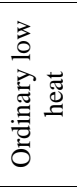 & 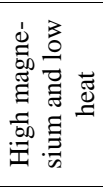 & 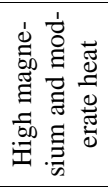 & & & 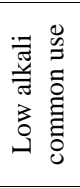 & $\begin{array}{l}\overline{0} \\
3 \\
3 \\
0 \\
0 \\
0 \\
0 \\
0 \\
0\end{array}$ & 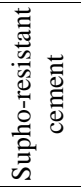 & 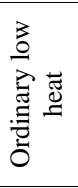 & 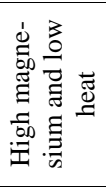 & 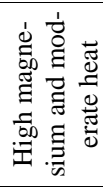 \\
\hline \multirow{6}{*}{ 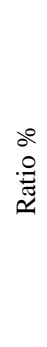 } & Limestone & 82.90 & 82.20 & 81.20 & 79.50 & 69.00 & 72.20 & \multirow{6}{*}{ 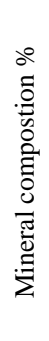 } & & & & & & & \\
\hline & Shale & & & & & 12.00 & 11.50 & & $\mathrm{C}_{3} \mathrm{~S}$ & 61.42 & 62.16 & 49.06 & 33.81 & 29.56 & 50.93 \\
\hline & Copper slag & & 6.50 & 6.50 & 6.50 & 6.00 & 6.30 & & $\mathrm{C}_{2} \mathrm{~S}$ & 14.06 & 15.95 & 28.81 & 45.07 & 44.18 & 25.03 \\
\hline & Dolomite & & & & & 11.00 & 10.00 & & $\mathrm{C}_{3} \mathrm{~A}$ & 9.12 & 1.11 & 1.34 & 1.26 & 2.09 & 1.60 \\
\hline & Red sand & 9.90 & 11.30 & 12.30 & 14.00 & & & & & & & 16 ว & & 1620 & \\
\hline & Aluminum tail & 7.20 & 13.55 & & & 2.00 & & & 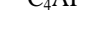 & 10.04 & $10.2 J$ & 10.20 & 10.02 & 10.39 & 13.00 \\
\hline \multirow{6}{*}{ 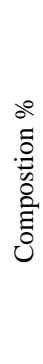 } & Loss & 34.53 & 33.33 & 32.96 & 32.37 & 33.34 & 33.95 & \multirow{6}{*}{ 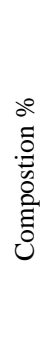 } & Loss & 1 & 1 & 1 & 1 & 1 & 1 \\
\hline & $\mathrm{SiO}_{2}$ & 12.71 & & 14.37 & 15.89 & 14.68 & 13.59 & & $\mathrm{SiO}_{2}$ & 20.95 & 21.80 & 22.86 & 24.54 & 23.12 & 22.03 \\
\hline & $\mathrm{Al}_{2} \mathrm{O}_{3}$ & 2.97 & 1.76 & 1.83 & 1.97 & 2.20 & 1.78 & & $\mathrm{Al}_{2} \mathbf{O}_{3}$ & 5.68 & 3.85 & 3.93 & 3.85 & 4.24 & 3.90 \\
\hline & $\mathrm{Fe}_{2} \mathrm{O}_{3}$ & 2.16 & 3.49 & 3.51 & 3.50 & 3.53 & 3.32 & & $\mathrm{Fe}_{2} \mathrm{O}_{3}$ & 3.50 & 5.36 & 5.35 & 5.27 & 5.39 & 5.15 \\
\hline & $\mathrm{CaO}$ & 44.31 & 44.67 & 44.14 & 43.59 & 40.88 & 42.66 & & $\mathrm{CaO}$ & 64.82 & 64.22 & 63.11 & 62.34 & 59.33 & 61.90 \\
\hline & MgO & 0.85 & 1.06 & 1.06 & 1.05 & 3.24 & 3.03 & & MgO & 1.31 & 1.59 & 1.58 & 1.55 & 4.75 & 4.46 \\
\hline \multirow{3}{*}{$\stackrel{\cong}{\frac{\Xi}{\pi}}$} & KH & 1.086 & 1.069 & 0.991 & 0.879 & 0.876 & 1.013 & \multirow{3}{*}{ 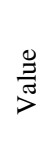 } & KH & 0.924 & 0.917 & 0.855 & 0.788 & 0.779 & 0.87 \\
\hline & $\mathrm{N}$ & 2.48 & 2.58 & 2.69 & 2.90 & 2.56 & 2.66 & & $\mathrm{~N}$ & 2.28 & 2.37 & 2.46 & 2.69 & 2.40 & 2.43 \\
\hline & $\mathbf{P}$ & 1.38 & 0.5 & 0.52 & 0.56 & 0.62 & 0.54 & & $\mathbf{P}$ & 1.63 & 0.72 & 0.73 & 0.73 & 0.79 & 0.76 \\
\hline
\end{tabular}

Source: Inside information of Jiahua enterprise.

Table 3. The adjustment of method and parameter of process technology control changes the performances of a part of products.

\begin{tabular}{|c|c|c|c|c|}
\hline Product & Standard & $\begin{array}{l}\text { The adjustment of } \\
\text { method and parameter } \\
\text { of process technology } \\
\text { control }\end{array}$ & Purpose & Note \\
\hline $\begin{array}{l}\text { Sulpho-aluminate cement } \\
\text { (type A) }\end{array}$ & & $\begin{array}{l}\text { Calcine clinker at } \\
\text { normal temperature }\end{array}$ & Satisfy the requirement of standard & $\begin{array}{l}\text { Standard } \\
\text { product }\end{array}$ \\
\hline $\begin{array}{l}\text { Sulpho-aluminate cement } \\
\text { (type B) }\end{array}$ & GB 20472-2006 & $\begin{array}{l}\text { Light burn clinker } \\
\text { appropriately }\end{array}$ & $\begin{array}{l}\text { Besides satisfying the requirement of standard, it } \\
\text { increases the content of f-CaO to shorten setting } \\
\text { time so that the color of clinker gets lighter. It's } \\
\text { suitable for European style decoration. }\end{array}$ & $\begin{array}{c}\text { Customized } \\
\text { product }\end{array}$ \\
\hline $\begin{array}{l}\text { Sulpho-aluminate cement } \\
\text { (type C) }\end{array}$ & & $\begin{array}{l}\text { Over burn clinker } \\
\text { appropriately }\end{array}$ & $\begin{array}{l}\text { Besides satisfying the requirement of standard, it } \\
\text { reduces the content of f-CaO to lengthen setting } \\
\text { time so that the color of clinker gets darker. It's } \\
\text { suitable for European engineering grouting. }\end{array}$ & $\begin{array}{c}\text { Customized } \\
\text { product }\end{array}$ \\
\hline $\begin{array}{l}\text { High magnesium and } \\
\text { moderate heat Portland } \\
\text { cement (type B) }\end{array}$ & GB 200-2003 & $\begin{array}{l}\text { Calcine thin clinker at } \\
\text { fast rotary speed }\end{array}$ & $\begin{array}{l}\text { Besides satisfying the requirement of standard, in } \\
\text { improves MgO activity to increase early stage } \\
\text { hydrated expansion furthermore and compensate } \\
\text { the concrete shrinkage. It's suitable for arch dam. }\end{array}$ & $\begin{array}{c}\text { Customized } \\
\text { product }\end{array}$ \\
\hline
\end{tabular}

Source: Inside information of Jiahua enterprise. 
Table 4. The process technology control parameters of a part of special cement products of Jiahua.

\begin{tabular}{|c|c|c|c|c|c|}
\hline Item & \multirow{2}{*}{$\begin{array}{l}\text { Production per } \\
\text { machine (ton) }\end{array}$} & \multirow{2}{*}{ Primary air $(\mathrm{Pa})$} & \multirow{2}{*}{ Secondary air $(\mathrm{Pa})$} & \multirow{2}{*}{ Tertiary air $(\mathrm{Pa})$} & \multirow{2}{*}{ Temperature of calciner $\left({ }^{\circ} \mathrm{C}\right)$} \\
\hline Product & & & & & \\
\hline Low alkali common use cement & 68 & 25,000 & 5200 & 120 & 870 \\
\hline Class G oil well cement & 68 & 25,000 & 5300 & 120 & 870 \\
\hline $\begin{array}{l}\text { High magnesium and moderate heat } \\
\text { cement }\end{array}$ & 68 & 27,000 & 5300 & 140 & 880 \\
\hline High magnesium and low heat cement & 70 & 28,000 & 5400 & 150 & 890 \\
\hline Ordinary low heat cement & 69 & 27,000 & 5300 & 140 & 880 \\
\hline Sulfate resistance cement & 69 & 25,000 & 5200 & 130 & 870 \\
\hline
\end{tabular}

Source: Inside information of Jiahua enterprise.

even suspended the production as kiln system breakdown during product conversions.

In earlier practices Emeishan Qianghua company produced class $G$ oil well cement and moderate heat Portland cement in the same calcining kiln production line. The factory made success at one time when converting class $\mathrm{G}$ oil well cement production to moderate Portland cement production with one time material input, which was because the similarity of the components of two products was very high and the compatibility of "permutoid" was great.

There were also failure cases when the enterprise practiced flexible production. In October 2008, the enterprise closed an ordinary kiln which was used to produce sulpho-aluminate cement. In order to keep customers, Qianghua factory tried to convert to produce sulpho-aluminate cement from producing class $\mathrm{G}$ oil well cement and moderate heat Portland cement. As the components of class $G$ oil well cement are high ferric and low aluminium, while the components of sulpho-aluminate cement are high sulfate, high aluminium and low ferric, they are extremely hard to compatible. During the conversions the rotary kiln broke down as the blocked materials in the kiln. The factory spent total five days to clear out the blocked materials and then put into production again. Similarly, during the conversions from sulpho-aluminate cement to class $G$ oil well cement the same broke down happened again and the factory had to stop production, clear out blocked materials and put into production again. Therefore, it can be seen that not all cement products are suitable for the CP in the same production line.

As the pressure of finishing orders, Leshan Jiahua cement factory needs to product 6 kinds of products every month and in peak period the factory will convert production as high as 13 times. After a period of experiences, Leshan Jiahua cement factory found out the regulars of sequencing production conversions, which is similar to the allelopathy theory. For example, the effect of con- verting class $G$ oil well cement production to low heat Portland cement product would be very poor, while the effect of converting class $\mathrm{G}$ oil well cement production to highly sulfate resistance cement first and then to low heat Portland cement would be great. This regular has been applied to other factories of the enterprise too.

See Figure 2 as the product sequencing chartf a part of special cement of Leshan Jiahua factory.

The factory illustrates the following sequence:

1) The $\mathrm{KH}$ of low alkali common cement and class $\mathrm{G}$ clinker is the same and the control indexes of $\mathrm{Fe}_{2} \mathrm{O}_{3}$ and $\mathrm{Al}_{2} \mathrm{O}_{3}$ are different. It just needs to adjust the control indexes of $\mathrm{Fe}_{2} \mathrm{O}_{3}, \mathrm{Al}_{2} \mathrm{O}_{3}$.

2) The control indexes of $\mathrm{Fe}_{2} \mathrm{O}_{3}$ and $\mathrm{Al}_{2} \mathrm{O}_{3}$ of sulpho-resistant clinker and class $\mathrm{G}$ clinker are the same and $\mathrm{KH}$ of sulpho-resistant clinker is lower than that of class $\mathrm{G}$ clinker. It just needs to adjust $\mathrm{KH}$.

3) The control indexes of $\mathrm{Fe}_{2} \mathrm{O}_{3}$ and $\mathrm{Al}_{2} \mathrm{O}_{3}$ of sulpho-resistant clinker and low heat clinker are the same and $\mathrm{KH}$ of low heat clinker is lower than that of sulpho-resistant clinker. It just needs to adjust $\mathrm{KH}$.

4) The control indexes of $\mathrm{KH}, \mathrm{Fe}_{2} \mathrm{O}_{3}$ and $\mathrm{Al}_{2} \mathrm{O}_{3}$ of common low heat clinker and high magnesium low heat clinker are the same. It just needs to adjust the content of MgO and alkali.

5) The control indexes of $\mathrm{Fe}_{2} \mathrm{O}_{3}, \mathrm{Al}_{2} \mathrm{O}_{3}, \mathrm{MgO}$ and alkali content of high magnesium moderate heat clinker and high magnesium low heat clinker are the same and $\mathrm{KH}$ of high magnesium moderate heat clinker is higher than that of high magnesium low heat clinker. It just needs to adjust $\mathrm{KH}$.

According to illustrations above and the data of Table 2, we find that the smaller the adjustment range of product components is, the easier the product production conversion is.

\subsubsection{Improvement of Product Conversion Control Technology}

The larger the adjustment range of product components, 


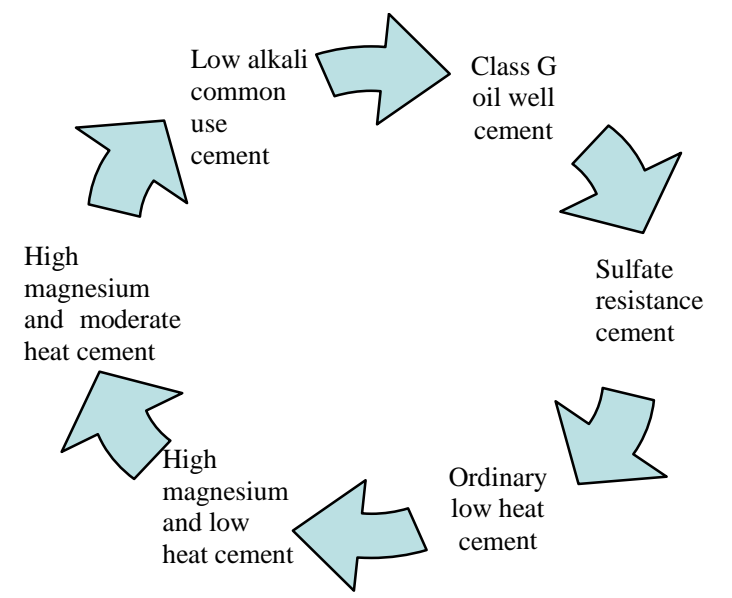

Figure 2. Product sequencing chart of a part of special cement. Source: Inside information of Jiahua enterprise.

the product production conversion will be the harder. It's noticed that it needs to solidify the control parameters and operation methods to a continuous process in order to push the production conversion more smoothly and stably.

Emeishan Qianghua Company experienced a lot of difficulties when converting production of class $G$ oil well cement to special cement for dam impervious wall. The cement is a kind of innovated product from low heat Portland cement and developed jointly by Yangtzi River Commission, owners and Jiahua enterprise. Besides there are obvious differences on the components compared with that of moderate heat Portland cement and class G oil well cement, the calcining temperature is $70^{\circ} \mathrm{C}$ lower than that of moderate Portland cement, so the factory didn't produce qualified products for two days after production conversion and got the qualified products in the third day, but the production cost was high, and a lot of alternate materials were wasted.

In the second half year of 2010, Jiahua Jinping Company in Liangshan State always complained that the customized slight expansion moderate heat Portland cement offered to Ertan Hydroelectric Development Corporation Jinping Power Station and Guandi Power Station cost too much as the selection rate of slight expansion moderate heat Portland cement was too low resulting too much wasted alternate materials. In order to solve the selection rate problem, Jiahua enterprise organized related technicians to analyze and found out that the light burning was the main reason for the problem as the variation value of burned temperature was too big, the rotary speed of kiln was faster and the weight per liter of clinker was lower. Finally, Jiahua Jinping Company improved the selection rate of slight expansion moderate heat Portland cement to above $95 \%$ just by adjusting a parameter in temperature area of the kiln.

After that Jiahua enterprise carried out a production promotion program, which was led by Engineering Centre. The program systematically summarizes and certifies the operation rules and control parameters of each factory and promoted the time table of modifying and perfecting the flexible manufacturing technology process quality manual and operation rules. In December 2010, all factories of the enterprise finished the modification work of manuals and rules.

\subsubsection{Reverse Development on Permutoid}

Frequent production conversion will absolutely influence the control of cost, among which the alternate wasted materials is a key factor that influence the cost of multiple products production.

Initially the way to recycle and reuse permutoid is mainly using it as the mixed materials for common cement 32.5. But as the price of common cement is too low, the way can't save too much cost.

Therefore, Jiahua enterprise had been always exploring the better utilization method for permutoid. Leshan Jiahua Cement Factory took the lead in getting that. On one hand, the factory tried to reduce the permutoid and improve the selection rate of qualified products in production conversion. On the other hand, the factory developed permutoid and special cement by adding permutoid into the high components special cement which has complementary relation with it or developing permutoid as the base material of functional mortar of Jiahua enterprise according to the components of permutoid so as to further improve the value of permutoid.

Now the ways Jiahua Cement Factory took have been popularized in the whole enterprise and all factories begin to compare the main economic technology of them with the common cement companies that produce common cement in mass production so as to reduce the production conversion cost to inconspicuous level.

The reverse development technology of permutoid brings value for permutoid which would be wasted materials, which actually is a kind of reverse product development technology conforming to utilization of Industrial wasted resources.

\section{Discussion}

\subsection{Flexible Manufacturing Model in CP Enterprises}

By quoting the classification view of economic system, we can view that CP is a closed system, by contrast, modularity process is an open system. The closed system will not have physical interaction with the external world but have energy and information interaction, whereas the open system will not only have energy and information interaction, but also have physical interaction (Zan Ting-quan, 2003) [12].

Therefore, as shown in Figure 3, CP can be illustrated 
as a process of input and output. In the process of raw material input and output, the system is closed and only has energy and information interaction.

In CP, the materials will have a series of physical and chemical reactions such as separation, decomposition, recombination and composition and finally product under the function of certain energy. The energy functions as a result of the combination of some kind of technology process control method and technology process control parameters, such as the increase or reduction of temperature, increase or reduction of pressure, increase or reduction of air volume, acceleration or deceleration of wind velocity and the transforming mechanical driving force and movement velocity of the material in the internal of the system. As the energy will function on the basis of consuming energy, it can explain why the energy cost in CP will have great influence on the competitiveness of enterprises.

Having entered the closed system, the material will move to the output terminal with appropriate transformation ways in the system and follow the sequence of technology process. The sequence of technology process can be illustrated as following. First, the technology process control method and technology process control parameters that the energy functions are distributed in the transformation spots of the material, for example, the temperature of the system may be lower when the material is input while it may be higher when the material is running in the middle of the system. Second, under the function of energy, the components in the internal of the material have physical or chemical reactions continuously in time order. Third, The material is in different status when it's in different transformation spot and the status of it has different physical or chemical nature in different transformation spot. Four, in the process of input and output of the material, there is some time-lag between the time point of material input and energy function.

The time order of the material inside the system can help us classify the technology process of CP as an unin terrupted production process, however, the relevant production process are not independent and the material inside the system doesn't have a clear physical interface, therefore, the classification of production process of $\mathrm{CP}$ is unrelated to modularity.

The control of energy is realized by the information transformation. The higher the automation degree of the closed system is, the more complicated the interaction on the external information will be. Therefore, it can be observed that the computer integrated control system has been applied on a large scale in CP industries such as cement industry, oil refractory industry and chemical industry.

\subsection{Categories of Flexible Manufacturing in CP Enterprise}

The production conversion of the multiple products in a single line of CP enterprise also follows time order. Technologically, there are two factors to drive product conversion, one is the components of raw material and the other is the means and parameter of technology process control when the energy functions. The Table 5 re flects what we think about the conversion method of CP. The vertical axis displays the change of components of raw materials and the conversion of drive products, which makes the production generate flexibility. The horizontal axis displays the means of technology process

Table 5. Flexible manufacturing model of CP enterprise.

\begin{tabular}{|c|c|c|}
\hline & $\begin{array}{l}\text { Unchange of the method } \\
\text { and parameter of } \\
\text { technology process } \\
\text { control }\end{array}$ & $\begin{array}{l}\text { Change of the method } \\
\text { and parameter of } \\
\text { technology process } \\
\text { control }\end{array}$ \\
\hline $\begin{array}{l}\text { Unchange of the } \\
\text { components of raw } \\
\text { materials }\end{array}$ & No flexibility & Control flexibility \\
\hline $\begin{array}{l}\text { Change of the } \\
\text { components of raw } \\
\text { materials }\end{array}$ & Component flexibility & Mixed flexibility \\
\hline
\end{tabular}

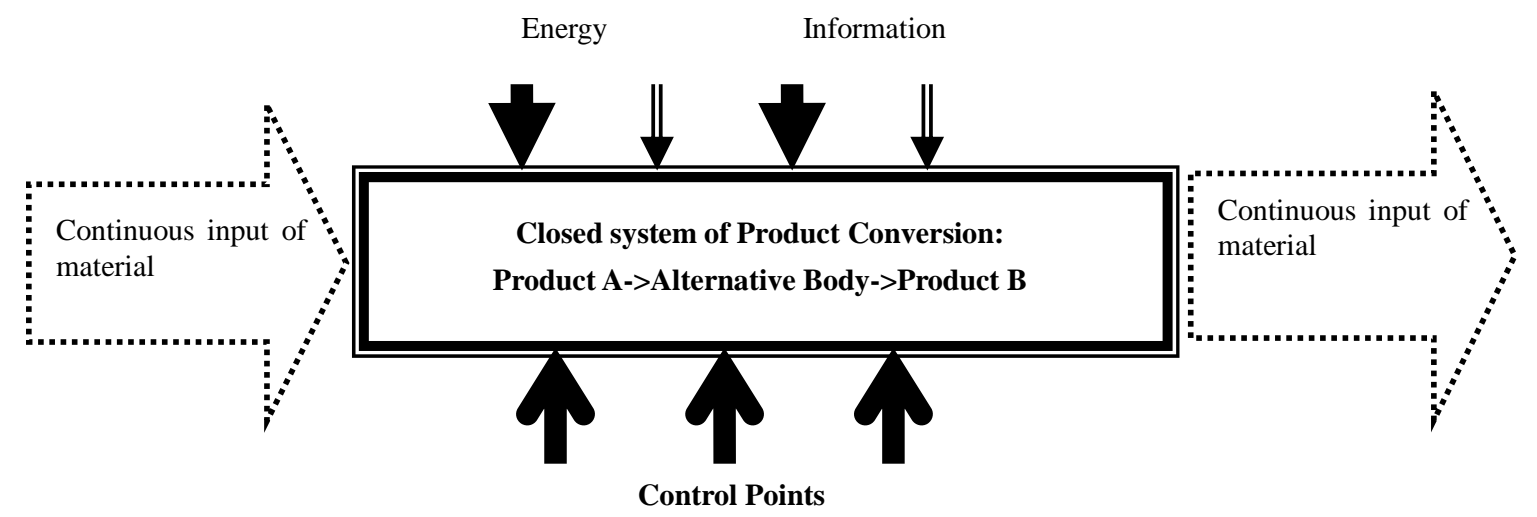

Figure 3. Continuous process of flexible manufacturing. 
control and the conversion of adjusting drive products of its parameter, which makes the production generate flexibility.

It can be seen from Table 5 that the flexibility of CP enterprises can function without relying on the group technology of modularity. On the premise that the components of raw materials, energy and parameters never change, the production line runs continuously in a single product production mode. Under the condition that the method and parameter of technology process never change, different products can be produced and the flexibility of manufacture is realized by adjusting the components of raw material , which we call Components Flexibility. Under the condition that raw materials never change, only adjust the method and parameter of technology process such as pressure, temperature, air volume and movement speed of material, it can also produce different products, which we call Control Flexibility.

Besides, in many cases the situation will happen, under which the components of raw materials and the method and parameter of technology process control all need to be adjusted and changed, we classify this kind of flexibility as Mixed Flexibility.

\subsection{Characteristics of Permutoid for Flexible Manufacturing in CP}

All CP enterprises concern the production process of the material input and product output. In order to realize the multiple products production in a single production line, under the condition of continuous production, whether it is component flexibility, control flexibility or mixed flexibility, it will output a product that is neither product A nor product $\mathrm{B}$ during the process of the production conversion between product $\mathrm{A}$ and product $\mathrm{B}$ as a result of the time-lag between material input and energy functions, which we call it Permutoid. Permutoid has the following characteristics:

\subsubsection{Compatibility}

Permutoid happens under the condition of adjusting the components of raw materials or changing the method and parameter of technology process control. Although it doesn't conform the standard of product A and B, the components between permutoid and product A and B have certain compatibility. Generally speaking, the better the compatibility of the permutoid is, the easier the conversion between two products will be. On the contrary, if the compatibility is very bad, even conflict with each other, the conversion of two products will be hard to realize under the CP. Therefore, the compatibility determines whether the product conversion is feasible or not technologically. Besides, the situation may happen under which the compatibility of the permutoid is worse when product $\mathrm{A}$ is converted to product $\mathrm{B}$, but better when it is converted to product $\mathrm{C}$, and the compatibility of the alternate bodies between product $\mathrm{C}$ and product $\mathrm{B}$ is not bad. Therefore, studying compatibility will help enterprise optimize the product production order in technical level.

Generally speaking, the similarity of the components of two products' raw material can improve the compatibility of the permutoid, the smaller the difference between two products' raw material, the better the components combine. In addition, the good compatibility between two products' raw material can also help to improve the compatibility of alternate bodies even though the components are quite different from each other.

\subsubsection{Continuity}

Permutoid is an intermedia in the product conversion process of two products. As the production process is always in a continuous state, the permutoid is also in such state, the permutoid will last till product $B$ is output after the production of product $\mathrm{A}$ is over. If the conversion is abnormal and the production process never terminates, the permutoid will last a long time. Therefore, the duration of the permutoid and its quantity will directly influence the conversion cost of the product.

Under the condition of the given raw material, the duration and quantity of the permutoid are related to the production control level. Generally, the less the method of technology process control increases or decreases and the smaller the magnitude of every parameter is adjusted, the shorter the duration of the permutoid becomes and the more smoothly the product is converted. Therefore, the smooth degree of conversion negatively corresponds to the adjusted variables of the method and parameter of technology process control.

\subsubsection{Reversibility}

The permutoid itself is a kind of substandard rejected material. However, it can largely reduce the conversion cost of CP enterprises if recycling, furtherdeveloping and reusing the permutoid with appropriate technology. What's more, furtherdevelopment of the permutoid usually produces a new product, which can increase the manufacturing flexibility. Therefore, the reverse development of the permutoid can also be viewed as a kind of flexible technology of CP enterprises.

\subsection{Strategic Choices for Large Scale Flexible Manufacturing in CP Enterprises}

According to the internal of enterprises, the key of large scale flexible manufacturing of CP enterprises is still how to solve reducing the production cost under the condition of mult-products production, which is similar to 
modularity enterprises.

Compared with the mass production in a single production line, all CP enterprises face the problem of product conversion cost for large scale and multiple production lines production. So how to reduce the conversion cost of the product is the focus for CP enterprises to carry out flexible manufacturing.

According to the analysis of the flexibility model and permutoid of CP enterprises, CP enterprises can adopt technical strategies below to reduce the conversion cost of flexible manufacturing, as shown in Table 6.

\section{Conclusions}

The exploration of flexible manufacturing of CP enterprise can help to extend the production methods of MC and flexible manufacturing to $\mathrm{CP}$ enterprise, which plays positive role in satisfying diversified and personalized requirement or consumers and customers and pushing more industries to carry out flexible production way.

Different from the strategy that modularized industries realize product manufacturing flexibility by standard and universal model design and systematic combinations, CP enterprises mainly create the variety of product by component flexibility, control flexibility and mixed flexibility. However, from the view of enterprises, both modularized enterprises and CP enterprises hope to realize the variety of product by mass production. Therefore, the flexible manufacturing of both modularized enterprises and CP enterprises is based on low cost.

Of course the key strategy for modularized enterprises and CP enterprises reverse to use toreduce the cost is different. CP enterprises pay more attention on permutoid, which arrange product production order appropriately by studying the compatibility of permutoid, shorten the show-up time of permutoid by integrating technology process control and promote the permutoid to be an avai-

Table 6. The technical strategy of reducing the conversion cost of CP enterprises.

\begin{tabular}{|c|c|}
\hline $\begin{array}{c}\text { Technical } \\
\text { strategy }\end{array}$ & The way to reduce the conversion cost \\
\hline $\begin{array}{l}\text { Product } \\
\text { sequencing } \\
\text { technology }\end{array}$ & $\begin{array}{l}\text { According to the compatibility of permutoid, } \\
\text { CP enterprises can push conversion, reduce the } \\
\text { quantity of permutoid, promote conversion } \\
\text { efficiency and reduce conversion cost by } \\
\text { optimizing product production sequencing. }\end{array}$ \\
\hline $\begin{array}{l}\text { Transform } \\
\text { control } \\
\text { technology }\end{array}$ & $\begin{array}{l}\text { According to the continuity of permutoid, } \mathrm{CP} \\
\text { enterprises can push conversion, shorten the } \\
\text { occurence time of permutoid, promote } \\
\text { conversion efficiency and reduce conversion } \\
\text { cost by optimizing process control technology. }\end{array}$ \\
\hline $\begin{array}{c}\text { Reverse } \\
\text { product } \\
\text { development } \\
\text { technology }\end{array}$ & $\begin{array}{l}\mathrm{CP} \text { enterpriss can reduce conversion } \\
\text { cost by recycling, redevelopment } \\
\text { and reusing the permutoid. }\end{array}$ \\
\hline
\end{tabular}

lable reverse product by redoveloping it so as to reduce the production conversion cost. While modularized enterprises realize low cost production by standard and universal model mass production.

The paper mainly discusses about flexible manufacturing technology of CP enterprise. Actually the study on the production organization management system related to CP flexible manufacturing is still a new subject. Besides, the writers also are thinking if there is any unique feature in product variety and customized requirement compared with modularized enterprises when considering from the view of customer. Lastly, there may be some new problems for us to pay close attention if we put flexible manufacturing of CP enterprises into supply chain relations.

The practice study in this paper can be extended furthermore. Logically, the flexible manufacturing model, permutoid theory and flexible strategy of CP enterprises can be extended to other CP industries such as glass industry, metallurgy industry, papermaking industry, chemical industry, pharmacy industry and so on from special cement industry. It can be judged whether the flexible strategy in special cement industry can explain the flexible strategy in those industries by further study.

\section{REFERENCES}

[1] J. Pine II , "Mass Customization: New Frontier of Enterprise Competition,” China Renmin UP, 2000.

[2] W. Christopher and L. Hart, "Mass Customization: Conceptual Underpinnings, Opportunities and Limits,” International Journal of Service Industry Management, Vol. 6, No. 2, 1995, pp. 36-45. doi:10.1108/09564239510084932

[3] K.-X. Dai and H.-X. Guo, "The Study of Core Competence of MC Enterprise,” Modern Management Science, Vol. 25, No. 3, 2006, pp. 66-67.

[4] A. K. Sethi and S. P. Sethi, "Flexibility in Manufacturing: A Survey," International Journal of Flexible Manufacturing Systems, Vol. 2, No. 4, 1990, pp. 289-328. doi:10.1007/BF00186471

[5] M. ko Aoki and A. Haruhiko, "Modularization Times-The Essence of New Industry Structure,” Shanghai Far East Press, Shanghai, 2003.

[6] G. U. Xin-jian and Q. I. Guo-Ning, "Quantitative Analysis Method of Mass Customization,” China Mechanical Engineering, Vol. 12, No. 6, 2001, pp. 312-315.

[7] Y.-H. Zhang, "Mass Customization Strategy for Customer Requirement,” Tsinghua University Press, Beijing, 2010.

[8] D. M. Anderson and J. Pine II, "New Frontier for Business Competition in the 21st Century-Agile Product Development under MC,” China Machine Press, Beijing, 1999.

[9] C. Y. Baldwin and K. B.Clark, "Managing in an Age of 
Modularity," Harvard Business Review, Vol. 75, No. 5, 1997, pp. 84-93.

[10] C. Y. Baldwin and B. Kim, "Clark Design Rules: The Power of Modularity,” MIT Press, Cambridge, 2000.

[11] J. Wang, "Production Operation Management," Tsinghua
University Press, Beijing, 2011.

[12] T.-Q. Zan, "Systems Economy: The Essence of New Economy-On the Theory of Modularity," China Industrial Economy, Vol. 20, No. 9, 2003, pp. 23-29. 